
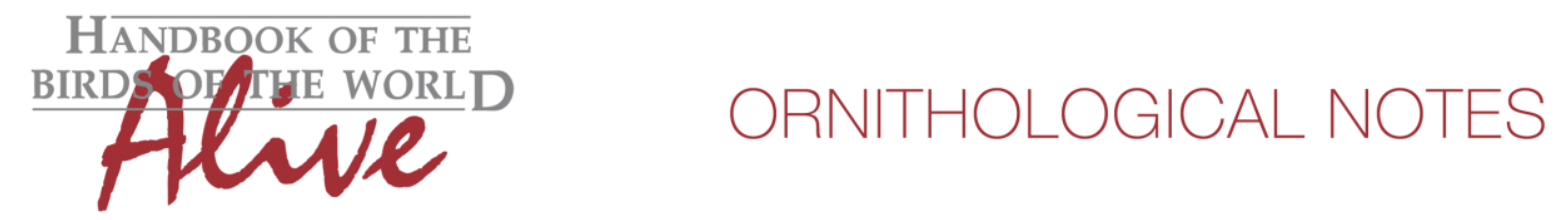

\title{
Notes on the vocalizations of Olive Sparrow (Arremonops rufivirgatus)
}

Peter Boesman

In the following we briefly analyze and compare voice of the different races of Olive Sparrow (Arremonops rufivirgatus). We also try to quantify the extent of any vocal differences using the criteria proposed by Tobias et al. (2010), as a support for taxonomic review.

We have made use of sound recordings available on-line from Xeno Canto (XC) and Macaulay Library (ML).

Song of all races is structurally similar, a series of strident notes with increasing pace, gradually changing from well-separated notes at first to a stuttering end.

Races can be grouped in the 'Northwest group'(rufivirgatus, ridgwayi and crassirostris), the 'Yucatan group'(verticalis and rhyptothorax) and the 'Pacific group' (superciliosus, sinaloae, sumichrasti and chiapensis) (sonograms of song for these groups in Attachment 1).

The 'Yucatan group' seems to have the most distinct song: the sequence of notes decreases in pitch towards the end (gradually reducing max. frequency) or there is a sudden switch to a different note with lower max. frequency (although this has also been noted occasionally in e.g. Oaxaca birds)(score 1-2). Furthermore, note shape is somewhat more complex, with clear bends visible on a sonogram vs. almost straight lines in both other groups (score 1 ). When applying Tobias criteria, this would lead to a total vocal score of at least 2.

The 'Pacific' and 'Northwest group' are probably not safely told apart.

Remark: XC28952 from C Honduras with song like Olive Sparrow suggests there may be an undescribed taxon there, unless it is an aberrant song of Green-backed Sparrow $A$. chloronotus, unlike other recordings of Green-backed Sparrow from Honduras and elsewhere.

This note was finalized on 24th May 2016, using sound recordings available on-line at that moment. We would like to thank in particular the many sound recordists who placed their recordings for this species on XC and $\mathrm{ML}$.

\section{References}

Tobias, J.A., Seddon, N., Spottiswoode, C.N., Pilgrim, J.D., Fishpool, L.D.C. \& Collar, N.J. (2010). Quantitative criteria for species delimitation. Ibis 152(4): 724-746.

\section{Recommended citation}

Boesman, P. (2016). Notes on the vocalizations of Olive Sparrow (Arremonops rufivirgatus). HBW Alive Ornithological Note 358. In: Handbook of the Birds of the World Alive. Lynx Edicions, Barcelona. (retrieved from http://www.hbw.com/node/1252900 on 28 October 2016). 
HANDBOOK OF THE

BIRDSPF/THE WORLD

\section{ORNITHOLOGICAL NOTES}

Attachment 1: Examples of song of the three groups of Olive Sparrow Arremonops rufivirgatus

"rufivirgatus group" (rufivirgatus, ridgwayi and crassirostris)

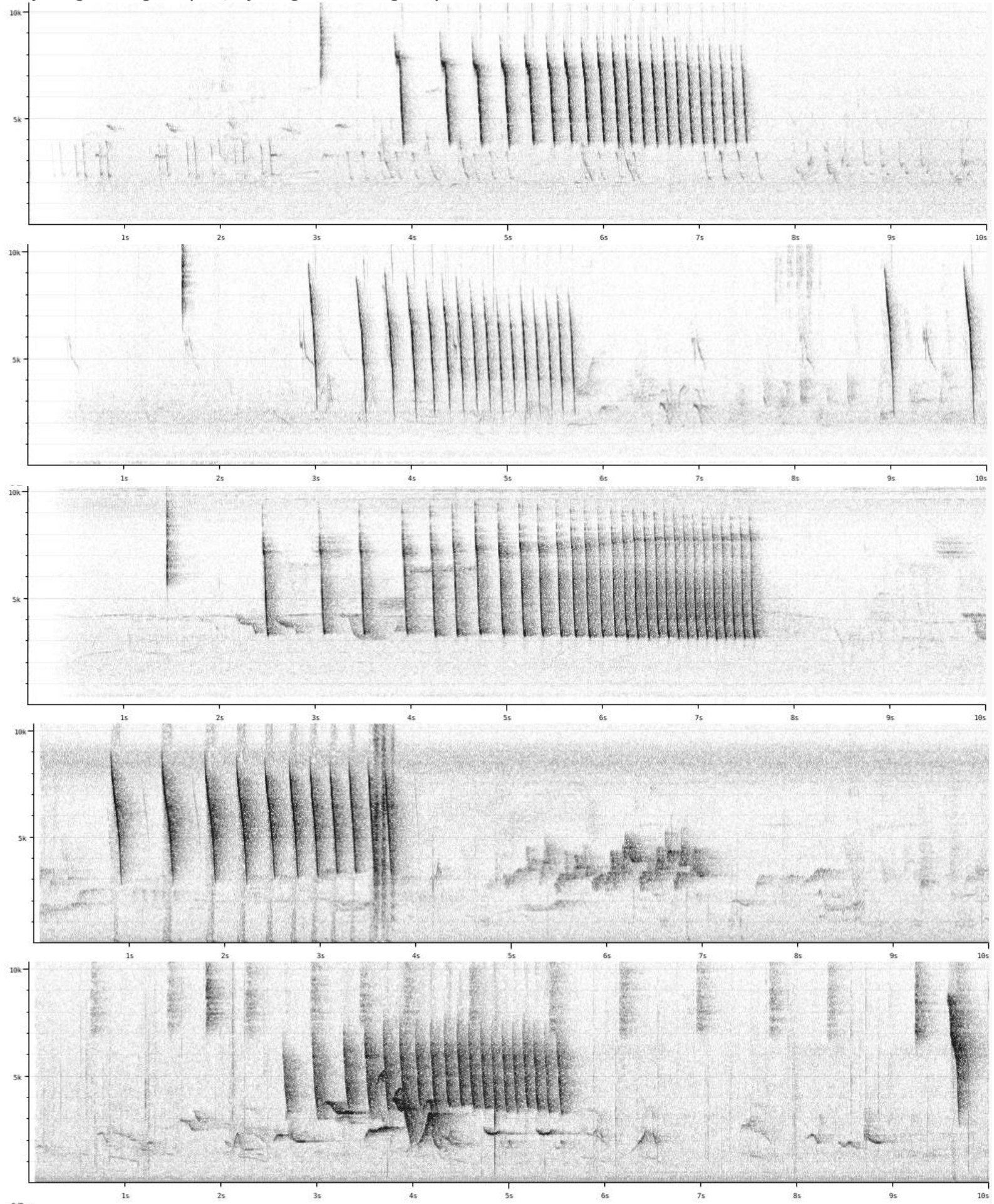


HANDBOOK OF THE

BIRDSPFGLE WORLD

ORNITHOLOGICAL NOTES

"Pacific group" (superciliosus, sinaloae, sumichrasti and chiapensis);

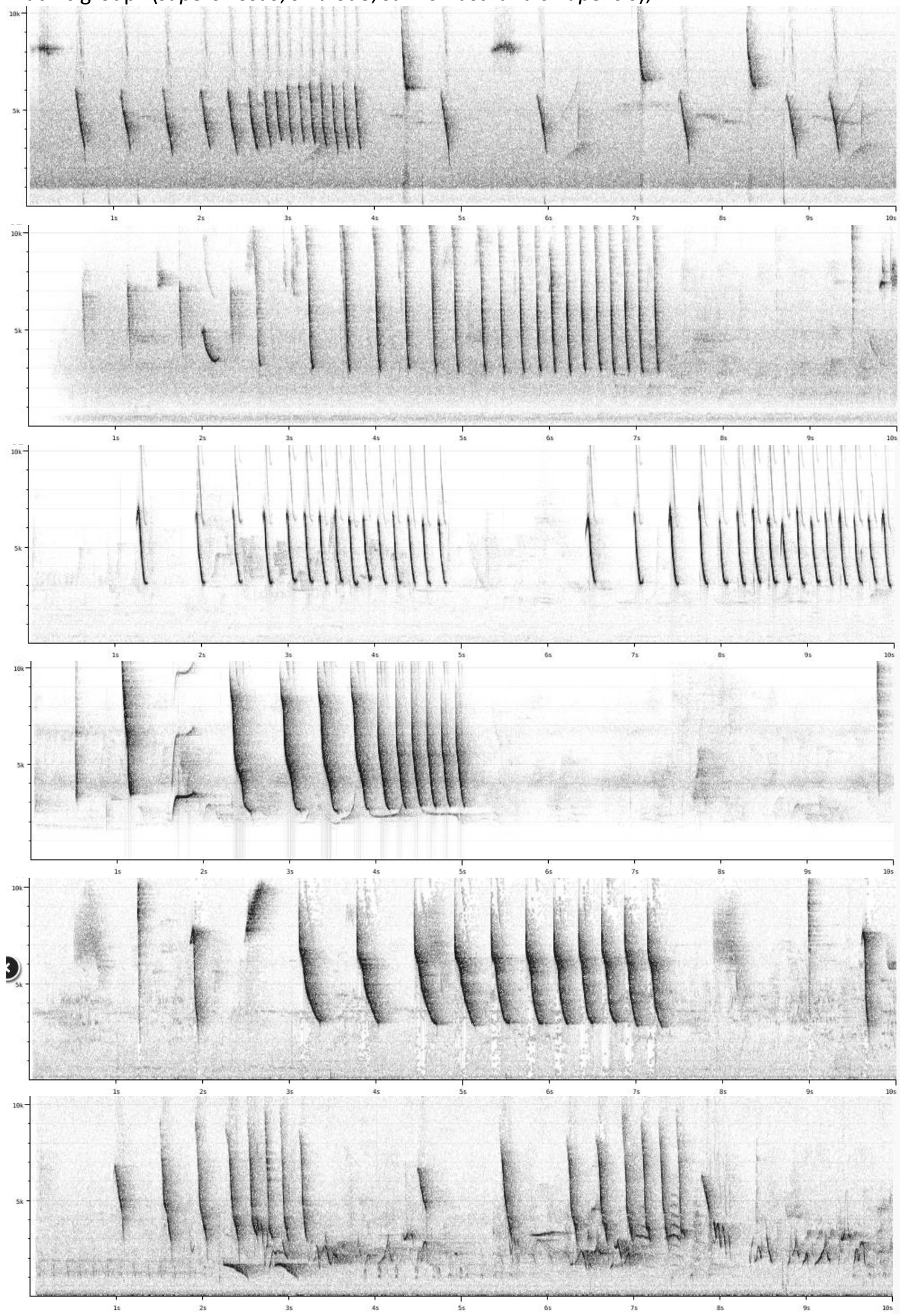


Alwe

ORNITHOLOGICAL NOTES

"Wuctan group" (verticalis and rhyptothorax)

